\title{
Surveillance \& Society \\ Surveillance as Communicating Relational \\ Article Messages: Advancing Understandings of the Surveilled Subject
}

\author{
Alana Saulnier \\ Department of Criminology, Law and Justice \\ University of Illinois at Chicago, US. \\ asauln3@uic.edu
}

\begin{abstract}
Theoretical understandings of how and why surveilled subjects perceive and react to surveillance have rarely been engaged in the field of Surveillance Studies. This research introduces relational models of procedural justice as a framework through which the attitudes and behaviours of surveilled subjects can be more consistently understood in particular (but not singular) surveillance contexts. Qualitative analysis of encounters with surveillance at Toronto Pearson International Airport, Canada demonstrates that participants were attentive to relational concerns during these encounters. The findings are positioned in relation to the procedural justice literature to demonstrate the importance of the process of surveillance alongside, or even apart from, its outcomes in terms of understanding and explaining surveilled subjects' experiences and formation of subjectivities at airports and perhaps more generally.
\end{abstract}

\section{Introduction}

Although the consequences of surveillance are a topic of focus in Surveillance Studies, consistent theoretical understandings of how and why surveilled subjects perceive and react to surveillance have rarely been engaged. Research has explored the micro-level of analysis, offering descriptions of surveillance experiences, but little work has employed theoretical lenses useful to understanding these encounters consistently across persons or contexts. This research introduces relational models of procedural justice to Surveillance Studies as a framework through which the attitudes and behaviours of surveilled subjects can be more consistently understood in particular (but not singular) surveillance contexts. Data describing encounters with surveillance authorities at Toronto Pearson International Airport (Pearson) is presented to support this assertion, demonstrating that participants were attentive to relational procedural justice concerns during these encounters. The findings highlight the importance of the process of surveillance alongside, or even apart from, its outcomes in terms of understanding and explaining surveilled subjects' experiences and formation of subjectivities at airports and perhaps more generally.

The work begins with a review of key literature; overviewing existing theories of the surveilled subject, and then introducing relational models of procedural justice. The method is described, highlighting participants, procedure and data analysis. Results and discussion sections then respectively present and discuss findings, demonstrating participants' attention to relational procedural justice concerns during encounters with surveillance at Pearson. The findings are situated in relation to literature on the surveillance of persons in 
movement at airports and more broadly, as well as work exploring surveillance as producing subjectivities of exclusion.

\section{Literature Review: Theorizing the Surveilled Subject}

\section{Surveillance Capital}

McCahill and Finn (2014) draw on Pierre Bourdieu to explore experiences of surveillance in the crime control context from the perspective of varied social groups (e.g., police officers, offenders, protestors). They introduce the concept of "surveillance capital" to describe "how surveillance subjects utilize the everyday forms of tacit knowledge and cultural know-how that is acquired through first-hand experience of power relations to challenge the very same power relations" (2014: 4). McCahill and Finn demonstrate the utility of the concept through an analysis of the ways in which participants contested surveillance across contexts. Their contribution offers insight on how diverse social actors differentially engage surveillance at the point of encounter, but, their emphasis is on the subject's negotiation of surveillance, with little discussion of the actual administration of surveillance. Alternatively, Ball's (2009) concept of exposure is much more attentive to the influence of procedure in theorizing the surveilled subject.

\section{Exposure}

Ball's (2009) work introduced the concept of "exposure," but her work on resistance (Ball and Wilson 2000; Ball 2005) are early forays into this same genre. Reactions ranging from acceptance to resistance follow encounters with surveillance, and explanatory theoretical models are needed to understand these reactions consistently across persons and contexts. Attention to the process of surveillance encounters are particularly important in this regard (Ball and Margulis 2011). Ball (2009) describes exposure as the individual's conscious sense of vulnerability, danger and visibility; maintaining that perceptions of exposure are a means by which individuals evaluate and react to encounters with surveillance. Di Domenico and Ball (2011) demonstrate the applied value of exposure in an analysis of B\&B operators' perceptions of encounters with secret inspectors, concluding that the concept offered some explanatory power in relation to participants' experiences. Ball, Di Domenico and Nunan (2016) further develop the concept by highlighting its utility in "new" surveillance encounters, discussing big data processes.

These contributions advance understandings of the surveilled subject. Ball draws attention to the surveilled subject's position and also considers how the process of surveillance affects perceptions of and reactions to surveillance. Across the contributions, exposure can be interpreted as being comprised of a number of process-oriented concerns, including: accountability (activity visibility), vulnerability (body interior, spatial/temporal privacy), awareness (relative invasiveness, preparedness, deception/covertness, procedural/outcome transparency), voice (data representation, interpretation and sharing), pleasure (voyeurism), power dynamics (process control, autonomy, consent/voluntariness), and proximity (interrelationality, lived normativities). However, understandings of how these concerns affect surveilled subjects' perceptions of and reactions to surveillance collectively through exposure are in their infancy. The procedural justice literature offers an alternative process-oriented model that is particularly well-suited to surveillance encounters that involve relatively direct interactions with surveillant authorities.

\section{Relational Models of Procedural Justice}

Surveillance often involves relationships of authority and subordination-a dynamic that is also central to procedural justice. As such, procedural justice research may be valuable in explaining surveilled subjects' experiences across persons and (some) contexts (especially law enforcement contexts that involve direct interactions between agents and targets of surveillance). Perceptions of the extent to which an outcome and authority are evaluated as fair and satisfying are heavily dependent on the procedure used to determine the outcome (Lind and Tyler 1988; Thibaut and Walker 1975). Particularly cogent is the procedural justice literature situated in legal contexts, which is concerned with evaluations of the application of law (emphasizing the subjective interpretations that define perceptions of justice) (Tyler 1989). 
The first explanations of procedural justice effects emphasized control; maintaining that people are concerned with procedures for instrumental reasons - desires to wield control over decisions (Thibaut and Walker 1975, 1978). However, relational explanations, emphasizing non-instrumental concerns, came to overshadow the control model in the legal context. Perceptions of group membership - whether someone feels included or excluded on the basis of treatment - are central to these explanations. Treatment that is attentive to relational concerns fosters feelings of in-group membership relative to administering authorities, while disregard for relational concerns promotes feelings of out-group membership that can lead to outgroup members feeling alienated (Bradford 2014; Lind and Tyler 1988). Multiple relational models have been developed to explain procedural justice effects, but the Group Value Model (Lind and Tyler 1988) is the dominant relational model employed.

The Group Value Model highlights relational concerns that shape procedural justice perceptions. Specifically, three relational concerns are identified: (1) neutral and consistent treatment; (2) trust in administrator benevolence; and, (3) interactions demonstrative of respect and dignity. Considerable empirical validation now exists to support the assumption that relational concerns drive perceptions of procedures and outcomes (Mazerolle et al. 2013; Tyler 1989), which has also revealed attitudinal and behavioural effects associated with procedural justice perceptions. In particular, procedures attentive to relational concerns have been found to enhance evaluations of outcome acceptance and satisfaction (Mazerolle et al. 2012; Mossholder, Bennet and Martin 1998; Tyler and Degoey 1995), support for and commitment to outcomes (Gibson 1989; Lind, Tyler and Huo 1997; Tyler and Degoey 1995), and perceptions of the legitimacy of specific outcomes and administering authority(ies) more generally (Bradford, Murphy and Jackson 2014; Sunshine and Tyler 2003; Tyler and Wakslak 2004). Legitimacy is a particularly important outcome here that carries over to surveillance encounters. Specifically, the perceived legitimacy of authorities (or institutions) prompts an attitude of compliance with the future instructions of those authorities (Sunshine and Tyler 2003), as well as more voluntary and cooperative behaviours, even to unpopular decisions (Gibson 1989; Sunshine and Tyler 2003; Tyler and Degoey 1995). These findings suggest a means by which surveilled subjects' perceptions of and reactions to surveillance procedures and authorities operating in law enforcement contexts could be more consistently understood.

Surveillance Studies, the Surveilled Subject, and Procedural Justice

Relational models of procedural justice maintain that treatment by an authority in a decision-making procedure is indicative of a decision-recipient's social status (Lind and Tyler 1988; Tyler and Blader 2000; Tyler and Lind 1992). When a surveillance encounter involves a direct (or relatively direct) interaction with some form of decision-making authority, surveilled subjects may evaluate their experience, its outcome, and the authority administering that outcome, at least in part, on the basis of relational procedural justice concerns. In particular, attention to relational concerns in Surveillance Studies may offer insight on the formation of surveilled subjects' subjectivities in terms of perceptions of in- or out-group status relative to surveillance administrators and, in turn, other surveilled subjects. Despite the emphasis in Surveillance Studies on authorities as agents of surveillance and the proven history of procedural justice in explaining perceptions of and reactions to interactions with authorities, procedural justice has received minimal attention in the Surveillance Studies literature.

Surveillance encounters have been linked to procedural concerns in the fields of organizational studies and occupational psychology in research focusing on the effects of employee monitoring (e.g., Alge 2001; Kidwell and Bennett 1994); but Ball's (2001, 2002, 2010) contributions acquainted Surveillance Studies with procedural justice. However, the framework is not central to these works, nor do any of the contributions engage with relational models of procedural justice. Although Surveillance Studies lacks research that has predominantly featured procedural justice, Ball's research highlights its relevance to the field by considering the relationship between procedures and outcomes. Her work suggests the value of looking to the procedural justice literature to better understand surveilled subjects' perceptions of and 
reactions to surveillance practices, personnel and technologies. More than that, relational models of procedural justice may offer a means to consistently theorize the surveilled subject in particular contexts; allowing the mechanisms at work in surveillance procedures to be better understood from the perspective of the surveilled subject, and the surveilled subjects' perceptions and behaviours to be more reliably explained.

\section{Method}

\section{Participants}

Participants $(\mathrm{N}=47)$ were recruited through (16) national and provincial community organizations that emphasized human rights focuses and one participating academic institution, with additional participants recruited via snowball sampling. Participation was contingent on self-identifying as: (1) a Canadian citizen or permanent resident, (2) having travelled through Toronto Pearson International Airport in the last three years, and (3) a racial non-minority or minority (with Middle Eastern, South Asian or Arabic heritage). ${ }^{1}$

The sample included the following self-identifications: 25 males and 22 females, 24 non-minorities and 23 minorities, and had a mean age of $30.74(\mathrm{SD}=11.25)$ years with a range of 18 to 60 years. As a nonprobability sample, the results cannot be generalized, but do provide preliminary insights into the utility of relational models of procedural justice for theorizing and explaining surveilled subjects' experiences in the context of airports specifically, borders more broadly, and perhaps encounters with surveillance in law enforcement contexts in general.

\section{Procedure and Data Analysis}

Participants' encounters with and perceptions of surveillance at Toronto Pearson International Airport were explored through semi-structured interviews. Participants were asked to relay their border crossing experiences at Pearson generally, but with a focus on security and customs encounters (e.g., expectations, typical and unusual encounters, self-awareness and manipulations during encounters), with guiding questions including probing into perceptions of processes (e.g., awareness of procedures and technologies, affective reactions, concerns), outcomes of procedures (e.g., comparative evaluations of treatment, response strategies), and understandings of "surveillance" in this context (e.g., definitions in theory and practice, positive and negative attributes). Interviews took approximately 60 to 90 minutes.

The research project from which this paper draws was driven by a more general focus of better understanding the position and perspective of the surveilled subject in surveillance encounters. A thematic analysis was used to sort and interpret the data, with the themes and categories discussed here informed by existing procedural justice literature. Four systematic reviews of the data were conducted, which involved isolating themes and reducing data through coding.

\section{Results}

Procedural Justice Concerns

\footnotetext{
1 The post-9/11 emphasis on "brownness" as an identity characteristic that warrants additional scrutiny coupled with anecdotal evidence suggesting that Canadian border crossing experiences are stratified, in part, by skin colour, prompted this participation criteria. One of the core qualities of "brownness" as it relates to surveillance (and border crossings in particular) is its "otherness," especially when juxtaposed to "whiteness" (Helleiner 2012). This phenomenon is captured by Patel's (2012) operationalization of "brown bodies" in relation to surveillance as "all those of Middle Eastern appearance, or of South Asian or Arabic heritage and of the Muslim faith...who are marked out as members of a 'suspect community"' (2012: 216).
} 
Participants were attentive to relational procedural justice concerns during encounters with surveillance at Pearson. While most participants emphasized the necessity of surveillant technologies and agents at this site, many also called the process into question. For instance:

I just want to state that...the authorities doing surveillance...in some situations is a requirement... but how they do surveillance, I think they need to do their homework a little bit.-Participant 20

So, it [surveillance] definitely has its place and I'm not sure how it can be...it can be improved just by treating people a little bit nicer or being a little less obvious of who you're targeting or profiling because I'm sure it doesn't feel good for those people. So, I think there's ways they can improve it that make it feel better for people.-Participant 10

Statements such as these demonstrate: (1) differentiating between processes and outcomes in relation to surveillance, and (2) implying attention to treatment-oriented concerns when encountering surveillance. However, the nuanced character of relational concerns was also articulated more explicitly (see Table 1).

\begin{tabular}{lcc}
\hline Concerns & References & Participants \\
\hline Respect & 14 & 13 \\
Trust & 26 & 16 \\
Neutrality & 100 & 36 \\
\hline
\end{tabular}

Table I. References to Relational Procedural Justice Concerns

\section{Respect}

Perceptions of respect are bound to evaluations of the extent to which treatment approximates appropriate status recognition, as demonstrated through interactions perceived as polite, dignifying and considerate of personal rights (Tyler 1994; Tyler and Lind 1992). Disrespectful treatment conveys low status within the group in question, and can also imply the relative positioning of groups in relation to one another (Tyler 1989). Participants demonstrated attention to respect through the indicators of: politeness, deservingness and voice.

Respect is perceived indirectly through indicators such as deservingness and opportunities for voice, but also more directly through tone and inflection; encompassed under "politeness" in the procedural justice literature (Tyler and Lind 1992). Tone was referenced by participants in describing encounters with officials at Pearson, and often characterized negatively through terms such as "rude," "abrupt" and "disrespectful." However, politeness was also dismissed as a highly valued indicator of respect due to the context. For example:

Sometimes the way they keep asking questions or probing, their tone can be, like, disrespectful, but I don't think...I just brush it off as their job.-Participant 14

While participants generally discussed politeness in terms of personal experiences, some mentioned seeing other travellers being spoken to disrespectfully. For instance: 
I know the last time I travelled that we were going through and there was a group of people standing in the line-up in front of me and their skin colour was brown and there was probably six or seven of them and they were all standing together and they were speaking a different language and there was that line at the metal detector area and me and my partner were called to go past them. It seemed like the tone of her voice was really friendly when she called us over and then, the group of other people, they asked: "Oh, should we come too?" And the way she said "No." to them was just like, almost rude...I don't know... it didn't seem as friendly. And, we almost felt like we shouldn't go, because we were like butting... but we did. So I feel like that is an example of it, like, clearly these other people were ahead of us in line, so why wouldn't they go through before us?-Participant 6

Participant 6's story helps illustrate the importance of politeness, demonstrating it is a criteria that participants were sensitive to even on behalf of others. Furthermore, the story suggests an awareness of the privilege of whiteness in this context, drawing attention to another indicator of respect: deservingness.

Perceptions of respect, as they relate to fairness, are founded in part in the relative accord between judgements of treatment received and treatment deserved (Heuer et al. 1999). Participants who spoke to this aspect of respect frequently characterized treatment by personnel at Pearson as failing to satisfyingly approximate that which was deserved. Participant 32 indicates attention to deservingness, highlighting perceptions of discord:

The actual...attitudes of the personnel conducting the surveillance searches...I'd say...I would generalize it...but at times they can be very rude and their authority can go to their head. It's not welcoming. It's more like you're entering a prison where you're constantly being watched. They don't care if you're not a threat, they're treating everyone the same.Participant 32

While Participant 32's characterization of deservingness suggests that respectful treatment is lacking, he describes it as uniformly lacking. Other participants perceived unwarranted scrutiny as more segmented. For instance:

It feels as though the greater good of the many is done at the cost of the few and if you're one of the few it's very negative and you don't appreciate the value to the greater good because you're that means. While I can intellectually sit back and say I sort of get it and see the value, I still have to physically go through it.-Participant 11

Participant 11 is expressing dissatisfaction with treatment that he sees as unjustified, but his speculation that a utilitarian philosophy underlies the treatment also draws attention to feelings of marginalization. Exclusion from active participation in a decision-making procedure is evaluated through perceptions of voice in the procedural justice literature. "Voice" refers to the opportunity to provide input during a procedure (Thibaut and Walker 1978), and is an indicator of respect in relational models (Lind, Kanfer and Earley 1990). While this aspect of respectful treatment is hinted at in the above quote, other participants addressed voice more directly.

Negative characterizations of voice emphasized perceptions of feeling helpless during the procedure. Participant 20 provides such an example:

When I was coming back one time, the guy beside me was having difficulty understanding what he was being asked because he didn't speak English well and so I translated it for him and both customs guards just looked at each other and they put something on my declaration card. Both me and that guy had to go to a different area that says "Newcomers to Canada." 
So, I walk back out and say "I'm not a newcomer to Canada," and the guy was just so extremely rude and said we had to go back in there. So I went back out again and said "Listen, I'm born and raised here," and he was extremely rude and I told him he couldn't talk to me like that, but we had to go back in and got asked all these questions about my wife and son - who was born overseas - and asked me a bunch of questions I don't recall the answers for and she was very insistent that I should have known the answers.Participant 20

This story demonstrates the silencing of voice at multiple levels. First, the decision made by the initial agent to send Participant 20 to secondary screening (which Participant 20 assumed was associated with his assistance to the other traveller), implied the "inappropriateness" of his behaviour; particularly that he had overstepped the role expected of him in this encounter. Second, Participant 20 describes being ignored when he explains that he has been sent to a screening area that does not align with his citizenship status. Finally, when questioned, Participant 20 felt that his responses were deemed insufficient (warranting additional scrutiny). In total, Participant 20's description of the encounter conveys strong feelings of being disrespected.

In summary, the concern of respect was embedded in 13 participants' narratives. At times, participants directly referenced the term "respect;" however, respect was frequently implicated through indirect indicators, specifically: politeness, deservingness and voice.

Trust

Trust involves evaluating the perceived intentions of authorities, specifically, reasonableness and benevolence (Tyler 1989, 1994; Tyler and Lind 1992). ${ }^{2}$ Perceptions of trust are particularly influential on perceptions of legitimacy (Hough et al. 2010; Tyler 1994). Participants demonstrated attention to trust through the indicators of: transparency and legitimacy.

Perceptions of benevolence are based on evaluations of the apparent effort dedicated to fair treatment in a procedure and the extent to which the outcome reached seems reasonable (Tyler 1989, 1994). However, decision-makers often have the power to use discretion, prompting evaluations of reasonableness to be based on the consistency of the procedure used to determine the outcome as opposed to the outcome itself. As such, procedural transparency has been identified as an aspect of procedural justice (Schafer 2013; Tyler 2004). Most participants who indicated a lack of trust did so through references to limited transparency, often linking feelings of unease with the (assumed) unbridled power of agents at Pearson. For instance:

The sense of being observed I don't mind too much. The knowledge that I could be observed in ways that I don't expect and that I think there's insufficient control over, that bothers me a little more...I don't think there's enough balance in oversight there.-Participant 24

Participants often assumed that there was little oversight in place for agents at Pearson-that decisions are made autonomously with little supervision - and the Canadian Border Services Agency is secretive about the policies and practices used to secure the border. National security serves as the justification for this opaqueness and, however legitimate that justification is, participants noticed the lack of transparency and associated it with a procedure that cannot be evaluated and is therefore somewhat untrustworthy. Participant 47 provides insightful comments in this regard:

2 This operationalization of "trust" is drawn from literature dedicated to relational models of procedural justice. Alternative bodies of literature (in particular, risk analysis, public administration, crime control and occupational psychology) also engage with the concept of trust, but somewhat differently, incorporating four sub-scales (integrity, benevolence, competence and procedural justice). 
I often miss my flight and that usually doesn't happen to people. I have to go to an office that most people don't have to go to. If they were being transparent...but they don't. You don't know how they're basing their decisions. I don't think it [surveillance] helps me in any way, but for the community it makes it more secure. However, I think if there was more transparency to it than I think it would make the community more secure. So, I don't know if it's really positive. There's security and stability, but those are just labels.-Participant 47

Airports are spaces that require the traveller to render themselves transparent (Hall 2007), but the relationship is not reciprocal - the surveillance procedures used by the administrator are less than wholly transparent to the traveller. When travellers can draw on other relational indicators (e.g., respect) to establish perceptions of in-group status, this lack of transparency may be less significant. However, concerns associated with transparency may be more substantial for travellers who also perceive other indicators of mistreatment (e.g., bias). Participant 47's quote exemplifies transparency as a dimension of trust and indicator of group status for surveilled subjects in such encounters. Furthermore, he suggests that security and stability (prime objectives of surveillance in the context of border crossings) would be enhanced by greater transparency. Ultimately, Participant 47 offers evidence that trust in a surveillance authority is linked to transparency (which then needs to reveal benevolence). Although this characterization is representative of the way trust was most frequently engaged with, trust can also be interpreted differently.

The procedural justice literature traditionally conceptualizes trust in terms of participants' perceptions of the trustworthiness of the authority; however, in the context of surveillance encounters, trust might also be conceptualized as the extent to which the surveilled subject perceives themselves as being trusted. Participant 23 explicates this second understanding of trust in describing her transition between an Indian to Canadian passport:

I wasn't always a Canadian citizen, I used to travel on an Indian passport. The interesting part being that when I had that passport I was travelling a lot for work and there would be a big group travelling and I would always get additional questions and be held up. Interestingly enough, it wasn't as pronounced when I got the Canadian passport. But I was the exact same person, no different markers but the Canadian passport. Does that make me a more trustworthy person? So, your identity, in the sense of citizenship, plays a huge role in border crossings. My crossings are not as seamless as yours [referencing the white female interviewer], but they're better... and the individual behind the passport has not changed, just the passport.-Participant 23

Participant 23's engagement with trust is used to describe how she does not feel trusted. This characterization of trust has not yet been considered in the procedural justice literature, but finds some support in the Surveillance Studies literature. For instance, Hasselberg's (2014) finding that surveillance impacts subjects' sense of self by making them feel untrustworthy, as well as McCahill and Finn's (2014) theoretical assertion that social bonds may be undermined through the use of invasive surveillance practices, potentially impacting normative compliance. This understanding of trust warrants further investigation and may be a unique quality of relational concerns in surveillance contexts.

Returning to the traditional characterization of trust, some participants linked mistrust to perceptions of legitimacy. For instance:

I have often felt that every...thing I say and answer I give-and this is obviously just a perception - is overly analyzed to the point where I'm constantly questioned. So, I'd give an answer, and what I think is a matter of fact answer is questioned, when I think there's no logical basis for the question. Which then leads me down a path that makes me wonder 
about the answers I'm giving, because it all seems like a very superficial experience, which makes me question why I'm even answering them.-Participant 11

When participants demonstrated attention to legitimacy - "a property of an authority or institution that leads people to feel that that authority or institution is entitled to be deferred to and obeyed" (Sunshine and Tyler 2003: 514) — it was via concerns associated with procedural transparency and trust.

In summary, the concern of trust was embedded in 16 participants' narratives. Similar to the concept of respect, participants directly referenced "trust," but also engaged with the concept through indirect indicators, specifically: transparency and legitimacy.

\section{Neutrality}

The most frequently referenced relational concern was neutrality. Neutrality broadly refers to the "evenhandedness" of a procedure (Lind and Tyler 1988), and is based on perceptions that treatment is unbiased, objective and administered with equality (Tyler 1994; Tyler and Lind 1992). Participants demonstrated attention to neutrality through the indicator of bias (systemic and individual).

Participants definitively maintained that consistent and equal exposure to surveillance across travellers was the expected norm. However, many participants relayed concerns over the extent to which procedures at Pearson are biased. Determinations of bias are based on perceptions of procedural inconsistencies (Tyler and Wakslak 2004). While some participants related first-hand experiences with biased treatment, most participants mentioned bias in more general terms by discussing how bias might be experienced by others, applied through hypothetical examples, or attributed on the basis of various identity characteristics. Although many identity characteristics were discussed in relation to neutrality concerns (i.e., race, ethnicity, accent, religious garb, criminal record, sex and age), country of origin was repeatedly emphasized as an attribute believed to be of particular significance to the distribution of treatment. For example:

I always feel like there are stereotypes about me because I'm from Iran...I always feel like there is some sort of racism there and that bothers me. I have that fear.-Participant 35

Furthermore, particular identity characteristics, when grouped together, were often implied to be the source for biased treatment-equating to more invasive surveillance encounters. In particular, country of origin/heritage, coupled with skin colour and assumed religion, were described as likely compounding exposure to biased treatment. While often discussed as potentialities, some participants related personal experiences that supported these assumptions. For instance, Participant 40 suggests that despite being a Canadian citizen, the facts that she was born outside of Canada (specifically in the Middle East) and sometimes travels with persons wearing (Islamic) religious garb contributes to lengthier encounters with agents at Pearson:

I come from a Lebanese background and get that stereotype of the Middle East and...not terrorist, but basically that you have to watch out for that person. A lot of personal experiences. They question us more than other people. So, we have to go through lengthy processes...like, if I'm with someone wearing something religious or cultural, we're more likely to be questioned by people.-Participant 40

Experiences like this may foster feelings of difference and exclusion, a possibility which is exemplified by Participant 11's summarization of how such encounters make him feel:

You almost feel... all of a sudden you become a secondary citizen if you want to put it that way, and the way I'm treated [at the border] is categorically different than the way I'm treated anywhere else.-Participant 11 
Although almost all participants discussing bias at Pearson cited identity characteristics such as skin colour, country of origin and religious affiliation as the assumed rationales underlying the bias, one participant described experiencing biased treatment based on a very different characteristic: a criminal record. Participant 1 provides a unique perspective framed by the challenges that his (pardoned) criminal record creates when crossing the border at Pearson to enter the United States specifically:

Now, if you've already proven to the right officials that you're not a threat any longer then I believe that that's where they stereotype because they know that I did this, but that ' $x$ ' amount of time has passed and the government has issued papers that say it's forgiven, then, I should just go through like anyone else who fits all the proper characteristics.-Participant 1

While exceptional, Participant 1's situation draws attention to the importance of neutrality in a way that is relatable to the previously presented experiences. Specifically, feelings of being identified as worthy of differential treatment based on immutable identity characteristics, culminating in the perception that the procedure is biased. However, concerns over neutrality were not only associated with systemic bias.

Evaluations of bias are also based on perceptions that personal biases are incorporated into decision-making processes (Tyler and Wakslak 2004). Many participants expressed anxieties over the possibility that treatment might be based on agents' personal biases. For example:

Where I feel different is feeling like there is some prejudice and bias in terms of the people conducting surveillance. The most direct one is certainly the visual minority aspect...I think it really just is a point at which the human factor comes in to determine what is a threat and what isn't a threat. There's no extended interaction at the border for people to focus on much else, so I know it matters.-Participant 3

In summary, the concept of neutrality was embedded in 36 participants' narratives. In combination, references to procedural consistency and agent discretion as indicators of bias highlight the centrality of neutrality concerns during encounters with surveillance at Pearson.

\section{Additional Considerations: Between Group Comparisons}

\section{Positive versus Negative Characterizations}

The data presented thus far has emphasized participants' negative characterizations of relational concerns during encounters with surveillance at Pearson, highlighting perceptions of disrespect, skepticism over trustworthiness, and bias. However, some participants described their encounters at Pearson much more positively. Due to space limitations, this data cannot be presented in detail, but participants were attentive to relational concerns regardless of whether relating positive or negative encounters. This provides evidence of participants' attention to relational concerns from varied frames of reference.

\section{Neutrality Concerns by Minority Status}

Procedural justice effects have been found to function similarly for persons regardless of identity characteristics, with demographic variables demonstrated to wield minimal influence on procedural justice concerns and evaluations (Feldman and Tyler 2012; Murphy, Hinds and Fleming 2008). Even cross-cultural comparisons suggest minimal variation in terms of the relational variables that constitute a fair procedure (Lind, Tyler and Huo 1997). However, given the concerns that cultural biases are embedded in surveillance policies and procedures at Canadian border crossings (see ICLMG 2010; Helleiner 2010, 2012), references to procedural justice concerns were compared by minority status. Participants' references to a single relational concern (neutrality) are focused on in the interest of space. Neutrality was selected because it was 
the most commonly referenced relational concern by the greatest number of participants. Some initial differences were evident in the volume of sources and references (see Table II).

\begin{tabular}{lcc}
\hline Minority Status & References & Participants \\
\hline Non-minority & 28 & 16 \\
Minority & 73 & 20 \\
\hline & \multicolumn{3}{c}{ Table II. References to Neutrality by Minority Status }
\end{tabular}

Minority participants indicated attention to neutrality concerns more often and with greater frequency than non-minority participants. Furthermore, the content of these references provide some support for Skogan's (2006) finding that people tend to be more attentive to procedural justice concerns when mistreatment is perceived. In other words, neutrality concerns are not more or less important to either group of participants, but, instead, that there may be asymmetrical experiences between minority and non-minority participants. The surveillance levied at borders is a manifestation of insecurity and suspicion, and, regardless of whether it is applied equally, these "neutral" applications are not necessarily interpreted as such by the targets of the surveillance. Post-9/11, the fanatical Muslim terrorist is a particularly high priority threat (Gopinath 2005; Puar 2005; Puar and Rai 2004), but persons bearing identity characteristics that approximate this threat may also be particularly scrutinized as potential "enemies within" (Aas 2007). In this context, applications of surveillance at airports and border crossings may be particularly suggestive of exclusion for persons who already perceive some degree of out-group status in the culture of a nation. Research has demonstrated that perceptions of ongoing enhanced surveillance scrutiny on the basis of immutable identity characteristics (such as race) that differ from dominant cultural standards foster perceptions of racialized subjectivities (Finn 2011); which, is arguably a perception of an out-group status. With an established out-group subjectivity, attention to relational messages communicated by surveillance may be particularly acute.

Participants routinely addressed the same general topics (i.e., bias/targeting, relative distributions of treatment across persons, and attitudinal and behavioural responses) and held similar overall positions, but there was considerable variation in the framing of these statements as well as the nature of the experiences divulged between minority status groups. While both minority and non-minority participants were attentive to neutrality concerns, highlighting the same focal points and generally corroborating the others' perceptions, participants' experiences were not described consistent across minority status: Minority participants expressed greater perceptions of and personal experiences with bias and unfairness.

Perceptions of racialized surveillance (i.e., surveillance patterned along racial lines and which produces discriminatory treatment, see Browne 2012b; Fiske 1998) are well exemplified through the pattern of findings associated with neutrality. Participants described perceptions of discriminatory treatment along racial lines, with minority participants expressing this concern more frequently than non-minority participants. This is not to suggest that the intention of surveillance in this context is to maintain a fixed racial order, but instead that othering practices do come to privilege whiteness in this context (Browne $2012 \mathrm{~b}$ ). As such, these findings offer an empirical demonstration of racializing surveillance. Though not physically stopping the individual from ultimately moving across the border, racialized outcomes were produced; for instance, that minority participants were more concerned with mistreatment. Minority participants' descriptions speak to experiences of "luminosity" (being rendered highly visible through surveillance; Browne 2012a), in a way that exemplifies the relationship between out-group statuses and perceptions of enhanced surveillance scrutiny.

\section{Recognizing Surveillance as Communicating Relational Messages}

Data analysis revealed that participants were attentive to relational procedural justice concerns during their encounters with surveillance at Pearson; in particular, the core concerns of respect, trust and neutrality were 
all embedded in a number of participants' narratives. For example, perceptions of respect were mentioned in relation to evaluations of whether treatment by agents of surveillance at Pearson approximated appropriate status recognition. These references align with early (Tyler 1989; Tyler and Lind 1992) as well as more recent contributions to the procedural justice literature (Bradford, Murphy and Jackson 2014; Mazerolle et al. 2012, 2013), by linking the concept of respect to interpersonal interactions that are perceived as polite, dignifying and considerate of personal rights. Voice was an indicator of respect that was especially emphasized by participants. As in the procedural justice literature, participants characterized voice as a measure of the respect that the surveillance procedure in general and the agent specifically bestowed on them.

Similarly, references to trust were embedded in participants' narratives, with comments focusing on the extent to which the surveillance procedure and agents at Pearson seemed trustworthy. As in the procedural justice literature, the concept of trust was connected to perceptions of reasonable and benevolent treatment (Tyler 1989, 1994; Tyler and Lind 1992). Participants were attentive to whether they found the procedure and its administering authorities to be trustworthy, and often questioned this important aspect of fairness on the basis of limited transparency. Procedures and authorities that yield low perceptions of trust have consistently been found to be associated with low perceptions of legitimacy (Murphy 2005; Sunshine and Tyler 2003; Tyler and Wakslak 2004). In line with these findings, participants' narratives often intertwined references to transparency and legitimacy through comments that also suggested positive correlations between these perceptions and trust.

Finally, many participants referenced the concept of neutrality. Participants' statements demonstrated compatibility with longstanding relational understandings of procedural justice effects (Antrobus et al. 2015; Lind and Tyler 1988), by linking the concept of neutrality to interpersonal interactions that were perceived as unbiased, objective and administered with equality. Procedural justice research has traditionally found concerns over bias to be attributed to either general procedural inconsistencies or the application of personal bias by decision-makers (Murphy, Sargeant and Cherney 2015; Tyler and Wakslak 2004). Participants' engagement with bias was highly consistent with the literature.

The results suggest that participants are attentive to the treatment-oriented concerns that constitute relational models of procedural justice; not only by providing references to the concepts of respect, trust and neutrality directly, but also by collectively mentioning all of the indirect indicators of these concepts identified in the procedural justice literature. Therefore, the findings suggest that, in this context, surveilled subjects are attentive to relational procedural justice concerns. Furthermore, the results provide empirical support for the relevance of relational models of procedural justice as a means by which to consistently understand the variety of experiences of surveilled subjects. Specifically, the results sections pertaining to positive characterizations of procedural concerns as well as variations associated with minority status are highly useful in this regard. The findings reviewed in these sections demonstrate that even when participants characterized their experiences with surveillance at Pearson very differently, they engaged with procedural justice concerns consistently. Therefore, importantly, when participants indicated attention to relational concerns in this setting, the experiences they related varied but their concerns remained consistent. 


\section{Relational Concerns, Group Membership and Surveilled Subjects' Subjectivities at Airports}

Research has discussed surveillance at airports and border crossings as administrators enacting social sorting (e.g., differentially facilitating ability and speed of movement for persons) (Adey 2003, 2004; Lyon 2003). Possibilities of discrimination are a key concern associated with social sorting in these contexts. While actual mobility is an aspect of discrimination here, another aspect of discrimination is the relational messages sent about one's value relative to others. This research draws attention to the pivotal role that relational concerns play in surveilled subjects' perceptions of surveillance encounters at airports as discriminatory. For example, speed of movement communicates relational messages (i.e., whose time is more valued, who is more trusted) that give the surveilled subject an awareness of whether they are sorted into a valued in-group, or a devalued out-group. These group membership positions are also formative of subjectivities of belonging.

The airport, as a site through which mobility flows, is also a site that communicates understandings of global orderings and belonging (Aas 2007, 2011). Airport surveillance is interested in vetting someone's claim that they "belong" in the commercial travel space; sorting travellers into groups of those which are trusted, untrusted, or "about whom more needs to be known" (Curry 2004: 477). The means by which these conclusions are reached can alert the surveilled subject to the extent to which they are scrutinized by others as potentially not belonging. These interactions serve as an indicator (amongst many others in our lives) of our belonging within the culture of a nation, with implications for our identities and understandings of self (Aas 2007). As such, attention to relational concerns (i.e., respect, trust and neutrality) in the administration of surveillance is particularly important in this context to encourage perceptions of inclusion rather than exclusion. Surveilled subjects' attention to relational concerns here is not a new phenomenon, though it is one that is now more easily recognizable. People underwent less surveillance scrutiny in the early days of commercial air travel (Curry 2004). It is not that relational messages were not important during that time period, but simply that the relational messages communicated were largely demonstrative of in-group status. The emphasis now placed on vetting the traveller simply fosters greater recognition of relational messages indicative of group membership more generally (i.e., the scrutinizing of out-group members).

Practices of identification that are engaged during this vetting process have implications for identity in terms of individuals' understandings of themselves (Amoore 2006; Pallitto and Heyman 2008). The argument forwarded here is that relational messages communicated by surveillance practices are important in this regard. For example, the service entitlements (e.g., mobility rights) that accompany citizenship are associated with perceptions of belonging in a society (Isin and Turner 2007), however, the processes leading up to the fulfilment of such rights may be just as influential on perceptions of belonging. For instance, actual citizenship standing may feel somewhat compromised when authorities performing policing services related to national security (e.g., airport and border security personnel) fail to be attentive to relational, treatmentoriented concerns. Perceptions of disrespect, lack of trust and bias all contribute to evaluations of out-group status relative to administering authorities (Blader and Tyler 2003; Smith et al. 1998; Tyler 1989), which, in this context, may be equatable to sentiments of flawed citizenship relative to the more privileged status of persons whose treatment connotes in-group membership with administering authorities.

More broadly, encounters with surveillance at airports and borders send relational messages indicative of global privilege in terms of in- and out-group statuses. Global movement is governed by discourses of crime control and risk that impose positions of social exclusion for "others" deemed inherently suspicious (Aas 2011). Relational models of procedural justice offer insight on the important messages such suspicion conveys about the extent to which individuals and groups of persons are valued as global citizens or othered; making relational concerns an important aspect of how the logic of "us" versus "them" is maintained or can be overcome. Encounters with surveillance administered by law enforcement authorities, such as the airport experiences discussed here, can be informative of trends in lateral surveillance (Reeves 2012). The procedural aspects of surveillance enacted by authorities that foster perceptions of out-group statuses (i.e., 
inattention to relational concerns) may be mirrored by in-group members encouraged to engage in lateral surveillance activities (e.g., "if you see something, say something" style campaigns), thereby reinforcing divisions of inclusion and exclusion amongst persons. The construction of subjectivities of in- or out-group statuses presents opportunities to scrutinize the behaviour of potentially dangerous others by enlisting ingroup members as informal extensions to the formal surveillant assemblage. The creation of insider and outsider identities have long been valuable for recruiting citizens into state surveillance efforts (Parenti 2003, cited in Browne 2012b). Recognizing relational, treatment-oriented concerns as influential on the creation and maintenance of divisive group identities offers criteria that surveillance practices must be attentive to if surveillance is to avoid fostering feelings of exclusion.

\section{Theorizing the Experience of Surveillance}

Surveillance Studies will be advanced by seeking out or developing theories that are able to consistently explain and predict attitudes and behaviours associated with surveillance encounters. Robust theoretical explanations can be developed that will allow for contextually similar surveillance encounters across varied situations to be understood relatively consistently; allowing discrete research projects to pool knowledge and make more credible claims about findings to other academics, the public and practitioners. While the findings discussed here are most representative of the experiences of these 47 participants in this particular setting, they also offer a bridge to consider whether relational procedural justice concerns may be relevant for surveilled subjects in other law enforcement contexts.

The wealth of consistent findings in the existing procedural justice literature suggests that relational concerns may be valued in surveillance encounters more broadly. Namely, surveillance encounters that involve direct interaction with a decision-making authority are likely to be evaluated on the basis of similar concerns. This position is born from the longstanding foundation of relational understandings of procedural justice: that evaluations of experiences are shaped, at least in part, by concerns over the interpersonal functioning of groups, particularly the connection between individuals and authorities (Tyler 1994). Very few studies have explored if and how the procedural application of surveillance affects surveilled subjects' attitudes and reactions, but those that have demonstrate that process matters (see Di Domenico and Ball 2011; Hasselberg 2014; Hasisi and Weisburd 2011). As such, the theoretical models and measures associated with procedural justice provide the means for empirically forwarding understandings of surveilled subjects' experiences at airports and borders, as well as in relation to law enforcement more generally. Furthermore, procedural concerns are implicated in other efforts to theorize the surveilled subject's experience (i.e., exposure and surveillance capital). Future research efforts that seek to integrate exposure, surveillance capital and relational models of procedural justice may provide a more comprehensive understanding of surveilled subjects' experiences - with each fleshing out aspects of a more holistic theoretical model, offering greater breadth and nuanced explanatory value both within and across surveillance encounters.

\section{Conclusion}

Participants were attentive to relational procedural justice concerns in describing their encounters with surveillance at Pearson. This finding offers important direction for future studies exploring surveilled subjects' affective, attitudinal and behavioural responses to encounters with surveillance in this context as well as others. For instance, the relevance of relational concerns during technologically mediated encounters warrant exploration. Surveillance at airports has only become increasingly technologically mediated since its inception (Adey 2003). Exploring how technologically mediated versus interpersonal interactions with surveillance administrators are associated with differential attention to relational concerns is a key future research direction that will cast further light on the surveilled subjects' experiences and subjectivities at airports, and potentially in relation to surveillance administered by law enforcement more broadly. Likewise, further research is needed to tease out better understandings of surveilled subjects' evaluations of the relational messages communicated by varied interactions with surveillant persons, technologies and 
programs at airports and borders. For example, encounters with scrutinising surveillance at airports and borders may not always be interpreted as communicating relational messages of exclusion. "The surveillance of socially privileged populations seems to be driven by a different set of objectives and consequences than the surveillance of those at the bottom of the social hierarchy" (Aas 2011: 337). Enrolment in initially more invasive surveillance programs that ultimately lead to speedier travel (e.g., NEXUS for Canadian/U.S. border crossings) may actually be interpreted as communicating relational messages of inclusion rather than exclusion.

Procedural justice perceptions have been demonstrated to produce important consequences, many of which are relevant to understanding the effects of surveillance; most importantly, that the process, as much as the outcomes, of surveillance may be very influential on surveilled subjects' perceptions of inclusion, sending important relational messages about group membership. Relational models of procedural justice offer a set of criteria by which to demand more ethical surveillance practices that are useful for advancing surveillance as for rather than of people (Stoddart 2012) by highlighting the importance of surveilled subjects' perspectives when evaluating applications of surveillance. As such, the results of this research suggest that both academic understandings and practical applications of surveillance will be advanced through the continued integration of relational procedural justice concerns into efforts to theorize and understand surveilled subjects in Surveillance Studies.

\section{Acknowledgements}

I would like to thank the anonymous reviewers from Surveillance \& Society as well as David Lyon and Kirstie Ball, who all provided helpful feedback that improved the quality of the material presented in this manuscript at various stages of its development.

\section{References}

Aas, K.F. 2007. Analyzing a world in motion: Global flows meet 'criminology of the other.' Theoretical Criminology 11(2): 293303.

Aas, K.F. 2011. 'Crimmigrant' bodies and bona fide travelers: Surveillance, citizenship and global governance. Theoretical Criminology 15(3): 331-346.

Adey, P. 2003. Secured and sorted mobiliites: Examples from the airport. Surveillance \& Society 1(4): 500-519.

Adey, P. 2004. Surveillance the airport: Surveilling mobility/mobilising surveillance. Environment and Planning A 36(8): 13651380.

Alge, B.J. 2001. Effects of computer surveillance on perceptions of privacy and procedural justice. Journal of Applied Psychology 86(4): 797-804.

Antrobus, E., B. Bradford, K. Murphy and E. Sargeant. 2015. Community norms, procedural justice, and the public's perceptions of police legitimacy. Journal of Contemporary Criminal Justice 31(2): 151-170.

Amoore, L. 2006. Biometric borders: Governing mobilities in the war on terror. Political Geography 25(3): 335-351.

Ball, K.S. 2001. Situating workplace surveillance: Ethics and computer based performance Monitoring. Ethics and Information Technology 3(3): 209-221.

Ball, K.S. 2002. Categorizing the workers: Electronic surveillance and social ordering in the call center. In: Surveillance as Social Sorting, ed. D. Lyon. London: Routledge.

Ball, K.S. 2005. Organization, surveillance and the body: Towards a politics of resistance. Organization 12(1): 89-108.

Ball, K.S. 2009. Exposure. Information, Communication \& Society 12(5): 639-657.

Ball, K.S. 2010. Workplace surveillance: An overview. Labor History 51(1): 87-106.

Ball, K.S., Di Domenico, M.L. and Nunan, D. 2016. Big data surveillance and the body subject. Body and Society 22(2): $58-81$.

Ball, K.S. and Margulis, S.T. 2011. Electronic monitoring and surveillance in call centres: A framework for investigation. New Technology, Work and Employment 26(2): 113-126.

Ball, K.S. and D.Wilson. 2000. Power, control and computer-based performance monitoring: Repertoires, resistance and subjectivities. Organization Studies 21(3): 539-565.

Blader, S.L. and T.R. Tyler. 2003. A four component model of procedural justice: Defining the meaning of a "fair" process. Personality and Social Psychology Bulletin 29(6): 747-758.

Bradford, B. 2014. Policing and social identity: Procedural justice, inclusion and cooperation between police and public. Policing \& Society 24(1): 22-43.

Bradford, B., K. Murphy and J. Jackson. 2014. Officers as mirrors: Policing, procedural justice and the (re)production of social identity. British Journal of Criminology 54: 527-550.

Browne, S. 2012a. Everybody's got a little light under the sun: Black luminosity and the visual culture of surveillance. Cultural Studies 26(4): 542-564. 
Browne, S. 2012b. Race and surveillance. In: The Routledge Handbook of Surveillance Studies, eds K.S Ball, K.D. Haggerty and D. Lyon, 72-80. London: Routledge.

Curry, M.R. 2004. The profiler's question and the treacherous traveler: Narratives of belonging in commercial aviation. Surveillance \& Society 1(4): 475-499.

Di Domenico, M. and K.S. Ball. 2011. A hotel inspector calls: Exploring surveillance at the home-work interface. Organization 18(5): $1-22$

Finn, R. 2011. Surveillant staring: Race and the everyday surveillance of South Asian women after 9/11. Surveillance \& Society 8(4): 413-426.

Fiske, J. 1998. Surveilling the city: Whiteness, the black man, and democratic totalitarianism. Theory, Culture and Society 19(2): 67-88

Feldman, Y. and T.R. Tyler. 2012. Mandated justice: The potential problems and possible pitfalls of mandating procedural justice in the workplace. Regulation \& Governance 6(1): 46-65.

Gibson, J.L. 1989. Understandings of justice: Institutional legitimacy, procedural justice, and political tolerance. Law and Society and Review 23(3): 469-496.

Gopinath, G. 2005. Bollywood spectacles: Queer diasporic critique in the aftermath of 9/11. Social Text 23(3): 157-169.

Hall, R. 2007. Of Ziploc bags and black holes: The aesthetics of transparency in the war on terror. The Communication review 10(4): 329-346.

Hasisi, B. and D. Weisburd. 2011. Going beyond ascribed identities: The importance of procedural justice in airport security screening in Israel. Law and Society Review 45(4): 867-892.

Hasselberg, I. 2014. Coerced to leave: Punishment and the surveillance of foreign national offenders in the UK. Surveillance \& Society 12(4): 471-484.

Helleiner, J. 2010. Canadian border resident experience of the "smartening" border at Niagara. Journal of Borderlands Studies 25(3): 87-103.

Helleiner, J. 2012. Whiteness and narratives of a racialized Canada-US border at Niagara. Canadian Journal of Sociology 37(2): $109-135$

Heuer, L., E. Blumenthal, A. Douglas and T. Weinblatt. 1999. The generality of procedural justice concerns: A deservedness model of group value and self-interest based fairness concerns. Personality and Social Psychology Bulletin 25(10): 1279-1292.

Hough, M., J. Jackson, B. Bradford, A. Myhill and P. Quinton. 2010. Procedural justice, trust and institutional legitimacy. Policing: A Journal of Policy and Practice 4(3): 203-210.

International Civil Liberties Monitoring Group (ICLMG). 2010. Report of the information clearinghouse on border controls and infringements to travellers' rights. ICLMB. Available http://www.travelwatchlist.ca/updir/travelwatchlist/ICLMB Watchlist Report.pdf.

Isin, E.F. and B.S. Turner. 2007. Investigating citizenship: An agenda for citizenship studies. Citizenship Studies 11(1): 5-17.

Kidwell, R.E. and N. Bennett. 1994. Employee reactions to electronic control systems: The role of procedural fairness. Group \& Organization Management 19(2): 203-218.

Lind, E.A., R. Kanfer and C.P. Earley. 1990. Voice, control, and procedural justice: Instrumental and noninstrumental concerns in fairness judgments. Journal of Personality and Social Psychology 59(5): 952-959.

Lind, E.A. and T.R. Tyler. 1988. The social psychology of procedural justice. New York: Plenum Press.

Lind, E.A., T.R. Tyler and Y.J. Huo. 1997. Procedural context and culture: Variation in the antecedents of procedural justice judgments. Journal of Personality and Social Psychology 73(4): 767-780.

Lyon, D. 2003. Surveillance After September $11^{\text {th }}$. Cambridge: Polity Press.

Mazerolle, L., S. Bennett, E. Antrobus and E. Eggins. 2012. Procedural justice, routine encounters and citizens perceptions of police: Main findings from the Queensland Community Engagement Trial (QCET). Journal of Experimental Criminology 8(3): 343-367.

Mazerolle, L., S. Bennett, J. Davis, E. Sargeant and M. Manning. 2013. Procedural justice and police legitimacy: A systematic review of the research evidence. Journal of Experimental Criminology 9(2): 245-274.

McCahill, M. and R. Finn. 2014. Surveillance, Capital and Resistance: Theorizing the Surveillance Subject. New York, NY: Routledge.

Murphy, K. 2005. Regulating more effectively: The relationship between procedural justice, legitimacy, and tax non-compliance. Journal of Law and Society 32(4): 562-589.

Murphy, K., L. Hinds and F. Fleming. 2008. Encouraging public cooperation and support for Police. Policing \& Society: An International Journal of Research and Policy 18: 136-55.

Murphy, K., E. Sargeant and A. Cherney. 2015. The importance of procedural justice and police performance in shaping interactions to cooperate with the police: Does social identity matter? European Journal of Criminology 12(6): 719-738.

Mossholder, K.W., N. Bennett and C.L. Martin. 1998. A multilevel analysis of procedural justice context. Journal of Organizational Behavior 19(1): 131-141.

Patel, T.G. 2012. Surveillance, suspicion and stigma: Brown bodies in a terror panic climate. Surveillance \& Society 10(3/4): 215234.

Pallitto, R. and J. Heyman. 2008. Theorizing cross-border mobility: Surveillance, security and identity. Surveillance \& Society 5(3): 315-333

Puar, J. 2005. Queer times, queer assemblages. Social Text 23(3): 121-139. 
Puar, J. and A. Rai. 2004. The remaking of a model minority: Perverse projectiles under the spectar of (counter) terrorism. Social Text 22(3): 75-104.

Reeves, J. 2012. If you see something, say something: Lateral surveillance and uses of responsibility. Surveillance \& Society 10(3/4): 235-248.

Schafer, J.A. 2013. The role of trust and transparency in the pursuit of procedural and organisational justice. Journal of Policing, Intelligence and Counter Terrorism 8(2): 131-143.

Skogan, W.G. 2006. Asymmetry in the impact of encounters with police. Policing \& Society 16(2): 99-126.

Smith, H., T.R. Tyler, Y.J. Huo, D.J. Ortiz and E.A. Lind. 1998. The self-relevant implications of the group-value model: Group membership, self-worth, and treatment quality. Journal of Experimental Social Psychology 34(3): 470-493.

Stoddart, E. 2012. A surveillance of care. In: The Routledge Handbook of Surveillance Studies, eds K.S. Ball, K.D. Haggerty and D. Lyon, 369-376. London: Routledge.

Sunshine, J. and T. Tyler. 2003. The role of procedural justice and legitimacy in shaping public support for policing. Law and Society Review 37(3): 513-548.

Thibaut, J. and L. Walker. 1975. Procedural justice: A psychological analysis. New Jersey: Lawrence Erlbalm Associated.

Thibaut, J. and L. Walker. 1978. A theory of procedure. California Law Review 66(3): 541-569.

Tyler, T.R. 1989. The psychology of procedural justice: A test of the group-value model. Journal of Personality and Social Psychology 57(5): 830-838.

Tyler, T.R. 1994. Psychological models of the justice motive: Antecedents of distributive and procedural justice. Journal of Personality and Social Psychology 67(5): 850-863.

Tyler, T.R. 2004. Enhancing police legitimacy. The Annals of the Academy of Political and Social Science 593(1): 84-99.

Tyler, T.R. and S.L. Blader. 2000. Cooperation in groups: Procedural justice, social identity, and behavioral engagement. USA: Psychology Press.

Tyler, T.R. and Degoey, P. 1995. Collective restraint in social dilemmas: Procedural justice and social identification effects on support for authorities. Journal of Personality and Social Psychology 69(3): 482-497.

Tyler, T.R. and E.A. Lind. 1992. A relational model of authority in groups. Advances in Experimental Social Psychology 25: $115-$ 191.

Tyler, T.R. and C.J. Wakslak. 2004. Profiling and police legitimacy: Procedural justice, attributions of motive, and acceptance of police authority. Criminology 42(2): 253-281. 